Muro de la investigación, 2020(2): julio-diciembre

ISSN: $2523-2886$

Doi: https://doi.org/10.17162/rmi.v5i2.1321

\title{
La fábula: un recurso pedagógico para la enseñanza de valores
}

\section{The Fable: A Pedagogical Resource for Teaching of Values}

\author{
Salomón Vásquez Villanueva, ${ }^{1 a}$ Moisés Agustín Cristóbal, ${ }^{2 b}$ \\ Marina Del Águila Gonzáles ${ }^{3 c}$, Moisés Diaz-Pinedo ${ }^{4 d}$ y Yoselin Gisela Espinoza \\ Vásquez $^{5 a}$
}

ORCID iD: https://orcid.org/0000-0001-8824-6176
ORCID iD: https://orcid.org/0000-0003-3828-5665
ORCID iD: https://orcid.org/0000-0003-2343-4533
ORCID iD: https://orcid.org/0000-0002-2106-9934
ORCID iD: https $/ / /$ orcid.org/0000-0001-5021-8794

\author{
Universidad Peruana Unión, Perú145 \\ Universidad Nacional Daniel Alcides Carrion, Perú2 \\ Universidad Nacional de la Amazonia Peruana, Perú 3
}

Recibido: 03 de enero de 2020

Aceptado: 02 de junio de 2020

\section{Resumen}

Este artículo tiene el objetivo de leer y analizar las fábulas, que comprenden un recurso pedagógico en la enseñanza de valores. A fin de lograr este objetivo, se han diseñado los siguientes tópicos relativos a la fábula: características, tipos, valores didácticos y estructura. Por otro lado, los estudiantes se encuentran actualmente sumergidos en las TIC'S (Tecnologías de la información) buscando distracción, entretenimiento, pasatiempo, etc., con el propósito de satisfacer sus necesidades triviales, negativas y vulgares. Su preferencia se inclina a la navegación en internet en vez de abrir las páginas de un libro y educarse. Se hace evidente que, además de la falta de información, comunicación, educación, cultura y reflexión, se están perdiendo los valores necesarios para la educación integral. Por lo tanto, las lecturas y análisis de las fábulas como estrategia didáctica constituyen un recurso pedagógico para la enseñanza de valores, de una manera dinámica y divertida, permitiendo que el relato actúe de mediador durante el proceso de enseñanza-aprendizaje.

Palabras clave: fábula, educación, valores, valores didácticos, estructura y tipos de fábula, lectura

\begin{abstract}
The aim of this paper is to argue the role of reading and analyzing the fables: a pedagogical resource in the teaching of values. In order to achieve this objective, the
\end{abstract}

${ }^{1}$ Correspondencia al autor: email: salomonv@upeu.edu.pe 
following topics related to the fable have been designed: characteristics, types, didactic values and structure. On the other hand, students are currently immersed in the Informations and Communications Technologies (ICTs) looking for distraction, entertainment, hobby, etc., in order to satisfy their trivial, negative and vulgar needs. His preference is for internet browsing rather than opening the pages of a book and educating himself. It is evident that, in addition to the lack of information, communication, education, culture and reflection, the values necessary for comprehensive education are being lost. Therefore, the readings and analysis of the fables as a didactic strategy constitute a pedagogical resource for the teaching of values, in a dynamic and fun way, allowing the story to act as a mediator during the teaching-learning process.

Keywords: fable, education, values, didactic values, structure and types of fable, reading

\section{Introducción}

En la actualidad, la práctica de valores se ha desgastado notoria y continuamente, a la vista de todos, mucho más a la vista de los más conservadores, posiblemente por el crecimiento desmesurado de la tecnología, cuánto más por el uso excesivo e indiscriminado de la misma. En este sentido, parece que no hay un tiempo específico para leer, informarse, educarse de una manera entretenida, dejando al margen la presencia continua de los buenos hijos, los estudiantes y los ciudadanos. Estos problemas se manifiestan también en otros espacios: la casa, la calle, la iglesia y otros; en el contexto educativo formal, el aula es un espacio muy importante para la acción educativa, donde el docente observa y evalúa el comportamiento, la actitud, la acción del educando (Mejía Betacur, 2016).

A fin de lograr éxitos diversos, la institución educativa y el aula necesitan honestidad, responsabilidad y obediencia, entre otros; sin embargo, los sujetos protagonistas revelan más deshonestidad, irresponsabilidad y desobediencia. Con el devenir de los tiempos, los espacios académicos de las aulas se han complejizado, además se han constituido en espacios donde el gobierno y la autoridad no son visibles, tampoco tienen sus deslindes.

Asimismo, para el docente consagrado al quehacer académico, le resuenan las interrogantes: ¿qué hacer para lograr la honestidad, la responsabilidad y la obediencia de los estudiantes? ¿Es una tarea que le compete solamente a los docentes? ¿Qué función tienen los padres? ¿Dónde se aprenden y se practican más los valores, en el hogar, en la escuela, o en la universidad? ¿La sociedad y las autoridades públicas tienen también participación activa en este asunto? 
Frente a esta situación compleja e indescriptible a plenitud, se considera que la práctica de valores-específicamente en el aula-requiere estrategias pedagógicas; por eso, este estudio propone la lectura de fábulas como una estrategia pedagógica. En esta perspectiva, surge el objetivo de analizar la lectura de fábulas como un recurso pedagógico para la enseñanza de valores.

Cabe señalar que la responsabilidad de la educación en valores depende mucho de los padres, del tiempo que disponen ellos para enseñar y del ejemplo que proyecten hacia sus hijos. Incluso, algunos padres creen que el docente es el encargado de educar a sus proles; sin embargo, el papel de los maestros solamente consiste en reforzar los valores que los estudiantes traen de casa y enfocándose en enseñar las diversas materias que implican el grado (Leon Tolentino, 2018).

\section{Aproximaciones teóricas sobre los valores y las fábulas}

\section{Los valores: honestidad, responsabilidad y obediencia}

Cuando suena en la conciencia de los hombres y las mujeres el término valores, nacen algunas interrogantes: ¿qué trasmiten esos valores?, ¿qué producen los valores en las personas? "Los valores se manifiestan en cada persona a través de sus comportamientos, de sus actitudes y de la forma como enfrenta cada circunstancia que la cultura y la sociedad le va presentando. Entonces, a través de la educación debemos establecer vínculos sociales y valores compartidos que nos permitan el pleno desarrollo del ser humano que se refleje en un mayor sentido de pertenencia y solidaridad, capaz de transformarse a sí mismo y de transformar su contexto para bien común” (Mejía Betacur, 2016, p. 39). En forma frecuente, los valores básicos y requeridos son: la honestidad, la responsabilidad, la obediencia, entre otros.

\section{La honestidad}

La honestidad "es la verdad y esencia de cada una de las personas", "la forma de actuar de cada uno de los seres humanos en base a su forma de pensar", "ser justa en toda forma", íntegra, razonable, sincera, "empezando con uno mismo desde nuestro pensamiento" (Valle Mayorga, 2016, p. 35). Es decir, la honestidad trasluce la verdad, la esencia, la forma de actuación, la forma de pensar, la sinceridad, la integridad, la forma de pensar de las personas. 
Asimismo, Restrepo (2001, en Vega Luquequispe, 2018) argumenta que "la honestidad se refiere a una faceta del carácter moral y se refiere a los atributos positivos y virtuosos tales como la integridad, veracidad y sinceridad, junto con la ausencia de la mentira, el engaño o robo" (p. 37). En realidad, la honestidad se relaciona con la integridad; es decir, quien es honesta es integra, actúa con toda la verdad y la sinceridad; jamás miente, engaña y roba.

Por otro lado, para Esper (2007, en Valente Barrios, 2018), la honestidad es "ser sincero con uno mismo y con los demás: leal, cumplidor, responsable, razonable, justo, equitativo, recto, bondadoso" (p. 26). Muchas personas se engañan a sí mismas, también a los demás. La honestidad, en este caso conceptual, implica la lealtad, la responsabilidad, la justicia, la equidad, la bondad, la rectitud.

Ante esto, cabe añadir que los estudiantes constantemente mienten al maestro y a sus compañeros, son injustos en su trato, son irrespetuosos consigo mismos y con las personas quienes están a su alcance. No se preocupan en mejorar su carácter moral y van formando hábitos malos que degradan su personalidad (Valle Mayorga, 2016).

\section{La responsabilidad}

Lovato \& Palomino (2017) sustentan que "la responsabilidad es un valor que está en la conciencia de la persona, que le permite reflexionar, administrar, orientar y valorar las consecuencias de sus actos, siempre en el plano de lo moral"' (p. 15). Para los autores, la responsabilidad se administra desde la conciencia, en términos de reflexión, administración, orientación y valoración; es decir, la conciencia de la persona posibilita el ejercicio de las mismas.

Asimismo, la responsabilidad "es un valor que nos compromete a cumplir con las acciones que se nos han encomendado y recibir las consecuencias por aquella acción" (Alfaro Campos \& Caballero Aguero, 2018, p. 44). En otros términos, la responsabilidad corona el compromiso asumido de las personas, cuyas consecuencias no son sino positivas que garantizan la permanencia moral de las personas.

Por su parte Llanes (2001, en Valente Barrios, 2018) argumenta que "la palabra responsabilidad tiene la misma raíz de respuesta. Por eso, la persona responsable es quien da buenas respuestas sobre sus tareas. Por lo general, cumple su labor puntualmente, y con buena calificación. Cuando hay obstáculos que le impiden realizarla, la persona responsable avisa oportunamente sobre la imposibilidad de cumplir su cometido" (p. 30). Para el contexto educativo, este tercer concepto tiene mucha validez y funcionalidad. El 
estudiante responsable no se queda sin respuesta, siempre ofrece una respuesta comunicada a tiempo, actúa movido por la puntualidad, comunica a tiempo la imposibilidad.

La realidad muestra generalente que los protagonistas frecuentemente no presentan sus trabajos teóricos y prácticos en los tiempos determinados y consensuados; tampoco son responsables de sus actos, llegan tarde al aula, además interrumpen la clase, etc. Les cuesta mucho practicar este valor, porque los padres, ejemplos principales y determinantes, no lo practican (Alfaro Campos \& Caballero Aguero, 2018).

\section{La obediencia}

La obediencia es otro valor muy importante en el escenario educativo que la comunidad educativa protagoniza. Particularmente, este escenario contribuye a que los profesores y los alumnos desarrollen colaboración, participación y buenas relaciones de convivencia. En este contexto, la obediencia es "una actitud responsable de colaboración y participación a fin de garantizar buenas relaciones en la convivencia. Desde un punto de vista humanista la obediencia se relaciona con la armonía con los demás y por ende obedece a personas generosas al servicio de los otros, actuando siempre responsablemente" (Eslava Zapata et al., 2018, p. 68).

Es común observar en el ámbito educativo que los educandos no obedecen al docente, no respetan los acuerdos de convivencia, no realizan las actividades designadas y programadas en cada área; tampoco colaboran con el desarrollo de la clase, menos participan voluntariamente, no tienen una buena convivencia con sus compañeros, no hay muestras de armonía ni de servicio al prójimo, entre otros (Eslava Zapata et al., 2018).

Asimismo, es de señalar que los sujetos no practican, no desarrollan dichos valores (honestidad, responsabilidad y obediencia) son considerados personas no confiables. En este escenario educativo, se percibe la ausencia de la práctica e interiorización de valores, dejando a la vista la mala educación, cuyos sujetos serán afectados en sus dimensiones social, académica y profesional. Estas falencias y ausencias son muy visibles; además, perjudicarán a los hombres y a las mujeres, a la sociedad y a las instituciones durante el devenir del tiempo, dejando la construcción de un futuro funesto.

\section{La fábula}

\section{Precisión histórica y etimológica}


La presencia de la fábula se inició en la Edad Antigua, en Mesopotamia, dos mil años antes de nuestra era, con un enfoque educativo y moral, muy válido para el proceso de la enseñanza a los niños. En concordancia con su propósito, estos relatos fueron expandidos por diversos territorios durante la antiguiedad clásica; por ejemplo, en Grecia durante el siglo VI a.C., cuyo exponente y representante fue el célebre escritor Esopo, quien creó numerosas fábulas. En Roma, sus representantes fueron Horacio y Fedro, quienes se inspiraron en Esopo y fueron motivados a escribir relatos morales. Posteriormente, en la Edad Media la fábula fue difundida por varios autores: Romulus, Syntipas, Dositeo e Isopete. En el Renacimiento, nacieron varias fábulas de magníficos escritores; por ejemplo, Da Vinci, Alciato, Sá de Miranda o Napoleón (Silva Tarazona, 2017).

En palabras de Rodriguez (2010): "La palabra fábula proviene del latín, fabula y se la define como un breve relato literario ficticio, en prosa o verso, con intención didáctica frecuentemente manifestada en una moraleja final, y en el que pueden intervenir personas, animales y otros seres animados o inanimados. En la mayoría de las fábulas aparecen animales con características humanas como el habla, el movimiento, etc." (en Valle Mayorga, 2016, p. 24).

\section{Conceptos de fábula}

Morales (2015) refiere que "la fábula es una especie del género narrativo, de extensión breve y cuyos protagonistas son casi siempre animales, pero que hablan y razonan como seres humanos" (p. 30). Por su parte, Alvarado Guerrero \& Lavayen Tomalá (2016) sustentan que "una fábula es un texto de juegos protagonizado por animales que hablan y escrito en prosa o verso con una intención didáctica de carácter ético y universal formulada la mayor parte de las veces al final, en la parte denominada moraleja, más raramente al principio o eliminada ya que puede sobreentenderse o se encuentra implícita" (p. 14). Además, Calles (2016) sostiene que "la fábula trata de un breve relato literario ficticio con una intención didáctica que generalmente se manifiesta en forma de moraleja dirigida a mostrar algún modelo específico de comportamiento" (p. $6)$.

En suma, estos autores ofrecen un común denominador: en las fabulas los animales son los protagonistas. El segundo y tercer autores coinciden en determinar la 
presencia de la moraleja; aunque el primero presenta la moraleja en forma implícita. Es decir, la fábula además de ser un genero literario, tiene un propósito: difundir la moraleja.

\section{Características de la fábula}

Sobre la base de las ideas sustentadas por Rodríguez (2010, en Silva, 2017), se aprecia que la fábula presenta las características siguientes: brevedad narrativa, relato dialogado, conversación frecuente de animales, incorporación del narrador, pocos personajes, valores presentados mediante la moraleja, publicación en prosa, lenguaje claro, sencillo y comprensible y contenidos interesantes.

\section{Estructura de la fábula}

Rodríguez (2010, en Silva, 2017) sustenta que la fábula presenta la siguie nte estructura: inicio, desarrollo, conclusión y moraleja. El primero presenta personajes, espacio y tiempo, los cuales intervienen durante la dramatización. Por su parte, el desarrollo corresponde a la vivencia de los personajes: dificultades y otros. La conclusión viene a ser el final de la historia: breve y sujeta a la moraleja. Esta consiste en una enseñanza moral: el objetivo de la fábula.

\section{Tipos de fábula}

Guijarro y López (1998, en Alfaro \& Caballero, 2018) mencionan que han clasificado la fábula de acuerdo con "su procedencia, sus personajes y el lugar de la moraleja”. En la clasificación según su procedencia, se encuentran cinco tipos: esópica, milesiana, mitológica, literaria y moral. La esópica hace referencia al autor Esopo, quien fue el creador de diversas fábulas. La milesiana representa el cuento o novela inmoral, con el objetivo de entretener a los lectores de fábulas. La mitológica relata los hechos pasados en la historia. La fabula literaria simboliza las setenta y seis fábulas de Tomás de Iriarte. Por último, la fabula moral represent a las mil trescientas setenta y siete fábulas divididas en nueve libros, escritos por el autor Samaniego.

La clasificación de los personajes son los siguientes: apólogos, racionales o parábolas y mixtas. El primero representa a los personajes que son animales racionales; el segundo corresponde a los oyentes quienes son hombres. Finalmente, el mixto es una variación entre seres racionales e inanimados. Por ultimo, la clasificación de la moraleja 
se divide en dos partes: afabulación y posfabulación. En la primera, la moraleja se encuentra al principio del relato. En la segunda, la moraleja se encuentra al final del relato.

\section{Selección, propuesta pedagógica y lectura de fábulas con valores didácticos}

Procedimiento pedagógico para la selección

a) Determinar el valor que se desea interiorizar en los estudiantes

b) Leer varios libros y antologías de fábulas

c) Seleccionar tres fábulas por cada valor: honestidad, responsabilidad y obediencia.

Procedimiento pedagógico para la lectura de las fábulas

a) Leer cada fábula, en forma personal, por lo menos tres veces.

b) Leer cada fábula, en equipo de seis, por lo menos tres veces.

c) Compartir la lectura de cada fábula, por lo menos, a tres amigos alumnos de la misma institución educativa.

d) Compartir la lectura de cada fábula, por lo menos, a tres familiares: padre, madre, hermano.

e) Desarrollo del cuestionario: a) ¿Quién es el autor de la fábula? b) ¿Quiénes son los protagonistas de la fábula? c) Subraya los nombres de los protagonistas; d) escribe tres acciones de cada protagonista de la fábula; e) escribe tu opinión sobre cada protagonista; f) escribe la moraleja de la fábula; g) comenta la moraleja con compañeros de clase.

f) Organizar un portafolio académico: portada (nombre de la institución educativa, título del portafolio, nombre y apellidos del autor, nombre del asesor o docente, lugar y fecha), hojas preliminares (dedicatoria, agradecimientos, contenido), ficha de fortalezas (nombre de cinco fortalezas), ficha de debilidades (nombre de cinco debilidades), ficha de autoevaluación, ficha de valoración (a su género, padre, madre, hermanos, compañeros, profesores, Dios, autoridades, medioambiente), ficha de lectura personal, ficha de lectura del equipo, ficha de lectura de los tres amigos alumnos, ficha de lectura de los tres familiares, cuestionario desarrollado, reflexiones finales.

\section{Conclusión}

En este estudio se afirma que la lectura y enseñanza de fábulas constituye una herramienta pedagógica eficaz para la enseñanza y la interiorización de valores en las 
instituciones educativas, cuyos beneficiarios son los estudiantes; esto debería producir en ellos valores importantes como la honestidad, responsabilidad y obediencia, y a la vez su conducta sea observada en la institución educativa y en el ámbito familiar.

\section{Referencias}

Alfaro Campos, R. R., y Caballero Aguero, J. G. (2018). Influencia del taller de fábulas para el fortalecimiento de la práctica de valores: respeto y responsabilidad en los niños de 3 años del C.E.E. "Rafael Narváez Cadenillas" de la ciudad de Trujillo en el 2017. (Tesis de licenciatura). Universidad Nacional de Trujillo, Trujillo, Perú.

Alvarado Guerrero, A. L., y Lavayen Tomalá, W. J. (2016). Influencia de la fábula y cuentos como estrategia metodológica en el desempeño lector en el área de lengua y literatura de los estudiantes de noveno año de la unidad básica fiscal Nueve de octubre zona 8, distrito 2, de la provincia de Guayas, Cantón Guay. Universidad de Guayaquil.

Calles Civantos, F. (2016). La fábula como recurso para mejorar la expresión oral y escrita en Educación Primaria. (Monografia de pregrado). Universidad de Jaén, Cajamarca, Perú.

Eslava Zapata, R. A., Zambrano Vivas, M. V., Chacón Guerrero, E. J., González Júnior, H. A., y Martínez Nieto, A. J. (2018). Estrategias didácticas para la promoción de valores ambientales en la educación primaria. Aibi Revista de Investigación, Administración E Ingeniería, 6(2), 64-72.

Leon Tolentino, E. K. (2018). Las fábulas como aprendizaje de valores. (Tesis de licenciatura), Universidad Santo Domingo de Guzmán, Lima, Perú.

Lovato Yupanqui, V. P., y Palomino Guamani, S. M. (2017). Los valores en el desarrollo socioafectivo en los niños de educación inicial. (Tesis de licenciatura). Universidad Técnica de Cotopaxi, Latacunga, Ecuador.

Mejía Betacur, Y. A. (2016). La influencia de los cuentos tradicionales en el fortalecimiento de las dimensiones del desarrollo en niñas y niños del nivel preescolar. (Trabajo de Maestría). Universidad de Antioquía, Medellín, Colombia.

Morales Vilca, S. D. (2015). Las fábulas en la producción de comics en estudiantes de educación secundaria en la Institución Educativa - Adventista - Satipo. (Tesis de licenciatura). Universidad Nacional del Centro del Perú, Huancayo, Perú.

Silva Tarazona, S. T. (2017). Taller de dramatización de fábulas como estrategia 
didáctica, basado en el enfoque colaborativo, para mejorar la expresión oral en los estudiantes de $3^{\circ}$ grado " $B$ " de educación primaria, de la Institución Educativa $N^{\circ} 84129$ “César Vallejo”, distrito de Yau. Universidad Católica Los Ángeles de Chimbote, Chimbote, Perú.

Valente Barrios, A. A. (2018). Religiosidad e interiorización de valores en estudiantes de preparatoria en escuelas adventistas de la Unión Interoceánica. (Tesis de maestría), Universidad de Montemorelos, Nuevo León, México.

Valle Mayorga, M. Y. (2016). Las fábulas infantiles y su influencia en el valor de la honestidad en los niños y niñas de 4 a 5 años de la Unidad Educativa de Ambato de la ciudad de Ambato provincia de Tungurahua. (Tesis de licenciatura). Universidad Técnica de Ambato, Ambato, Ecuador.

Vega Luquequispe, L. R. (2018). La narración de cuentos infantiles en la práctica de valores en los niños (as) de 3 años de edad de la IEI No 294 Aziruni-Puno 2018. (Tesis de licenciatura). Universidad Nacional del Altiplano, Puno, Perú.

\section{Anexos \\ Lectura $\mathrm{y}$ análisis de fábulas}

\section{El pastorcito mentiroso}

(Fábula de Esopo)

Había una vez un pastorcito que cuidaba su rebaño en la cima de la colina. Él se encontraba muy aburrido y para divertirse se le ocurrió hacerles una broma a los aldeanos. Luego de respirar profundo, el pastorcito gritó:

— ¡Lobo, lobo! Hay un lobo que persigue las ovejas.

Los aldeanos llegaron corriendo para ayudar al pastorcito y ahuyentar al lobo. Pero al llegar a la cima de la colina no encontraron ningún lobo. El pastorcito se echó a reír al ver sus rostros enojados.

-No grites lobo, cuando no hay ningún lobo — dijeron los aldeanos y se fueron enojados colina abajo.

Luego de unas pocas horas, el pastorcito gritó nuevamente:

—iLobo, lobo! El lobo está persiguiendo las ovejas.

Los aldeanos corrieron nuevamente a auxiliarlo, pero al ver que no había ningún lobo le dijeron al pastorcito con severidad: 
-No grites lobo cuando no hay ningún lobo, hazlo cuando en realidad un lobo esté persiguiendo las ovejas.

Pero el pastorcito seguía revolcándose de la risa mientras veía a los aldeanos bajar la colina una vez más.

Más tarde, el pastorcito vio a un lobo cerca de su rebaño. Asustado, gritó tan fuerte como pudo:

— ¡Lobo, lobo! El lobo persigue las ovejas.

Pero los aldeanos pensaron que él estaba tratando de engañarlos de nuevo, y esta vez no acudieron en su ayuda. El pastorcito lloró inconsolablemente mientras veía al lobo huir con todas sus ovejas.

$\mathrm{Al}$ atardecer, el pastorcito regresó a la aldea y les dijo a todos:

-El lobo apareció en la colina y ha escapado con todas mis ovejas. ¿Por qué no quisieron ayudarme?

Entonces los aldeanos respondieron:

- Te hubiéramos ayudado, así como lo hicimos antes; pero nadie cree en un mentiroso incluso cuando dice la verdad.

Moraleja. Nadie cree la verdad en la boca del mentiroso.

\section{Los ratones y las comadrejas}

Los ratones y las comadrejas estaban continuamente peleando. Y la mayoría de las veces, eran las comadrejas las que ganaban. Los ratones se reunieron en asamblea para debatir por qué perdían, y llegaron a la conclusión de que era por falta de jefes:

- Necesitamos unos jefes que organicen las batallas y sepan dirigir al resto- dijo uno de los ratones.

$-¡$ ¿Cierto!- contestaron los otros.

- Es verdad- dijo otro de los ratones- Las comadrejas están muy bien organizadas, porque tienen algún líder que dirige al resto.

- No se hable más- sentenció otro de los ratones- Escojamos entre todos a dos o tres jefes.

Y los ratones escogieron, mediante votación, a tres de los suyos para que hicieran de jefes.

Los jefes ratones estaban muy orgullosos de haber sido elegidos. Sentían una gran responsabilidad. Sin embargo, en lugar de reunirse y planear la siguiente batalla, decidieron gastar el tiempo en preparar un atuendo de jefes dignos de su puesto. Así que 
se colocaron una capa y en la cabeza, unos cuernos. Y así se dirigieron, orgullosos, al campo de batalla.

Los ratones, sin embargo, volvieron a perder la batalla. Las comadrejas les persiguieron hasta la entrada de su ratonera, y consiguieron entrar todos menos los tres jefes, que, al haberse puesto unos cuernos en la cabeza, no cabían por la entrada. Las comadrejas se dieron con ellos un gran festín.

Moraleja. La responsabilidad es enemiga de la vanidad y te aparta de la muerte.

\section{El Cabrito y el Lobo}

(Fábula de Esopo)

Al salir doña Cabra del establo encargó a su hijo el cuidado de la casa, advirtiéndole el peligro de los animales que rondaban con intención de entrar en los establos para devorar el ganado.

No tardó en presentarse el enemigo: ¡Un lobo horrible, amiguitos míos, un lobo! que, imitando la voz de la cabra, llamó cortésmente a la puerta. Al mirar el cabrito por una rendija, vio al feroz carnicero $\mathrm{y}$, sin intimidarse, le dirigió este discurso:

-Bien sé que eres nuestro peor adversario y que, fingiendo la voz de mi madre, pretendes entrar para devorarme. Puedes marcharte, odiado animal, que no seré yo quien te franquee la puerta.

Moraleja. Obedece el consejo de tus padres y vivirás siempre feliz. 